\title{
Numerical Analysis of the Effect of Piston Cooling Gallery Design on Heat Transfer in an Internal Combustion Engine
}

\author{
Refik Cevirme ${ }^{1}$ and Ovun Isin ${ }^{1}$ \\ ${ }^{1}$ Department of Mechanical Engineering \\ Faculty of Engineering \\ Yıldız Technical University, 34349 Istanbul \\ Turkey
}

\begin{abstract}
Internal combustion engines are important machines that make human life easier. Internal combustion engines are developing day by day and higher power density engines are produced. Besides, strict standards of emission and fuel economy are forcing automotive manufacturers to produce environment-friendly engines. While manufacturers produce engines in accordance with these standards, they also do various studies in order not to reduce performance. One of the most important of these studies is the development of thermal management. Good cooling of internal combustion engine pistons, which are exposed to high pressures and temperatures during the combustion process, is an important consideration for the development of the thermal management. In this study; it is aimed to investigate the effect of design differences on piston cooling by using different designs for the cooling gallery located in the head region of an internal combustion engine piston. For this purpose, thermal analysis of an internal combustion engine piston was performed for different cooling gallery designs and the results of the analysis of each design were compared. In addition, the results of the analysis were compared with the heat transfer rates in the literature.
\end{abstract}

Key Words: Internal Combustion Engine, Piston, Cooling Gallery, Heat Transfer, Thermal Analysis.

\section{INTRODUCTION}

As specific power output increases in modern combustion engines, the pistons are subjected to increasing thermal loads. Efficient piston cooling is therefore required more frequently in order to ensure operational safety. In order to ensure sufficient heat dissipation from the piston and to reduce the temperature in the critical piston zones, various types of cooling are used, depending on the quantity of heat to be dissipated and the combustion process-diesel or gasoline [1]. Varghese et al. [2] have developed a computational model using the finite element analysis method for oil jet cooling of the heavy-duty diesel engine piston and observed that the piston temperatures decreased by about $40{ }^{\circ} \mathrm{C}$ when oil jet cooling was used. Luff et al. [3] examined the effects of piston cooling jets on piston temperatures, emissions and fuel consumption. The engine oil jets can be opened and closed, supplied from a separate pipeline. When the oil jets were switched off, an increase of $28-30{ }^{\circ} \mathrm{C}$ in the plunger, a small increase of 3\% in NOx, and a 5-10\% decrease in CO in the hot steady state operating condition were determined. Thiel et al. [4] conducted an experimental study based on a passenger car diesel engine to investigate the effect of the piston cooling gallery on the piston temperature. Different oil jet designs combined with cooling galleries were tested. As a result of the study, it has been proved that different configurations provide a decrease in piston temperature and the use of double nozzle and oil jet significantly increases the piston cooling efficiency. Yi et al. [5] modeled a 3D cooling gallery and simulated the movement of the cooling jet with a software for the heat transfer in the cooling gallery. It was found that the heat transfer coefficient reached to the maximum value at the entrance by the strong impact of the oil jet and dropped as it moved away from the inlet. The oil temperature showed a linear increase towards the exit of the gallery. Belmonte et al. [6] studied the heat transfer and mechanical stress effects of a gasoline engine piston using CFD software. They also analyzed the effects of cooling gallery on heat transfer and indirectly on emissions in a piston with cooling gallery. The piston model with cooling gallery was compared with piston model without gallery in terms of temperature results. With the presence of cooling gallery; temperature drop $33{ }^{\circ} \mathrm{C}$ in piston head region, $36{ }^{\circ} \mathrm{C}$ in ring area, $25^{\circ} \mathrm{C}$ in skirt area, $31{ }^{\circ} \mathrm{C}$ in piston region and $29{ }^{\circ} \mathrm{C}$ in pin socket was observed. The aim of Kelleher and Ajotikar [7] was to establish a CFD analysis approach to investigate the effect of the nozzle design on oil flow. In the CFD model, different types of nozzles were examined and a deviation greater than a uniform flow rate caused negative effects on the oil flow. Zhu et al. [8] conducted a simulation study to investigate the effect of the oscillating oil on the cooling characteristics of the high-density piston cooling gallery. Cooling gallery was modeled, the effect of oil filling rate on cooling was investigated and heat transfer was focused. Considering the results of the studies, the effects of design parameters were found to be oil filling ratio was $64.6 \%$, top surface width of cooling gallery was $19.8 \%$ and height of cooling gallery was $15.6 \%$. The CFD calculation was used to analyze 
these optimum values and the temperature of the original engine wall decreased by $8{ }^{\circ} \mathrm{C}$. Peng et al. [9] conducted a study to produce two types of nanofluids for the piston cooling gallery. They included copper and diamond nanoparticles in conventional engine oil, respectively. As a result of the analysis, $1 \%, 2 \%$ and $3 \%$ of the oil was nanofluids and heat transfer coefficient increased by $7.77 \%, 17,08 \%$ and $29,33 \%$ respectively. Umut Canvar, in his study [10], examined the structural and thermal stresses of the piston in general and, due to these stresses, examined the effects of mean stress in critical regions and carried out fatigue analysis. By using CFD analysis, 4 different geometries have been formed by considering some points in terms of strength in the pit geometry forming the combustion chamber. As a result of the analysis, it was found that $35 \%$ of the heat generated after burning was discarded by cooling gallery. In order to achieve better results, it is stated that the cooling gallery height can be increased, and the cooling gallery section geometry can be angled.

The aim of this study is to investigate the effect of design differences of the cooling gallery located on the piston head in an internal combustion engine piston on piston thermal management.

\section{MATERIALS AND METHODS}

In this study, a piston model has been designed with reference to a diesel engine piston in order to examine the effect of the piston head design on heat transfer in an internal combustion engine, and different cooling galleries have been designed on this piston model, and steady state thermal analysis has been performed in ANSYS simulation software. The main dimensions of the designed piston model are given in Table1 and the referenced motor specifications are given in Table2.

Table1. Main Dimensions of the Designed Piston

\begin{tabular}{|l|c|}
\hline \multicolumn{2}{|c|}{ Main Dimensions of the Piston } \\
\hline Diameter & $108 \mathrm{~mm}$ \\
\hline Height & $108 \mathrm{~mm}$ \\
\hline Skirt Length & $37 \mathrm{~mm}$ \\
\hline Piston Head Wall Thickness & $27 \mathrm{~mm}$ \\
\hline Pin Boss Diameter & $46 \mathrm{~mm}$ \\
\hline Pin Length & $88 \mathrm{~mm}$ \\
\hline
\end{tabular}

Table2. The Referenced Motor Specifications

\begin{tabular}{|l|c|}
\hline \multicolumn{2}{|c|}{ The Referenced Motor Specifications } \\
\hline Engine Type & 4 Stroke Diesel Engine \\
\hline Compression Ratio & $16,1: 1$ \\
\hline Combustion System & Direct Injection \\
\hline Cylinder Volume & 8,81 \\
\hline Ventilation & Turbocharged Cooled \\
\hline Weight & $864 \mathrm{~kg}$ \\
\hline
\end{tabular}

The designed piston consists of two sections. 


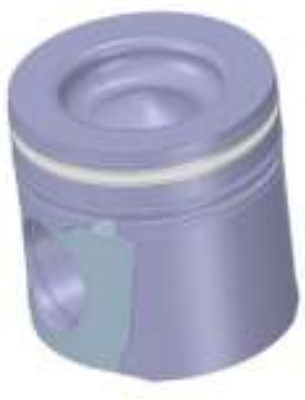

(a)

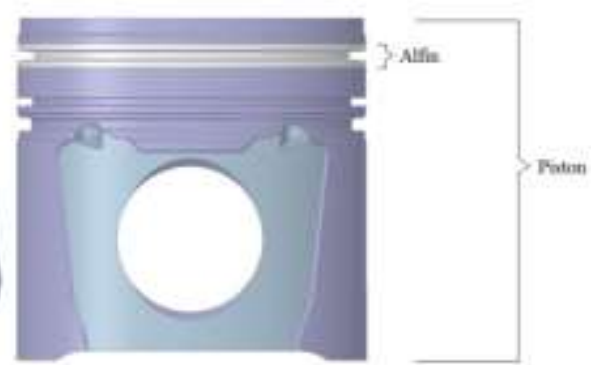

(b)

Figure1: a) Perspective View of Piston Model b) Front View of Piston Model

The piston model was taken in cross-section and three different cooling galleries in the literature were selected and designed in the inner area of the piston head. The first design is a symmetrical, common cooling gallery. The second design is asymmetrical and longer than the first design, and the third design is the geometry and length that will allow the cooling oil to perform cocktail shaking in the gallery.

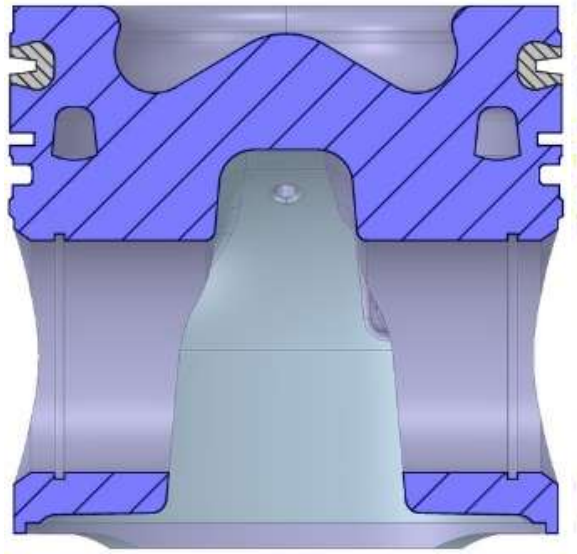

(a)

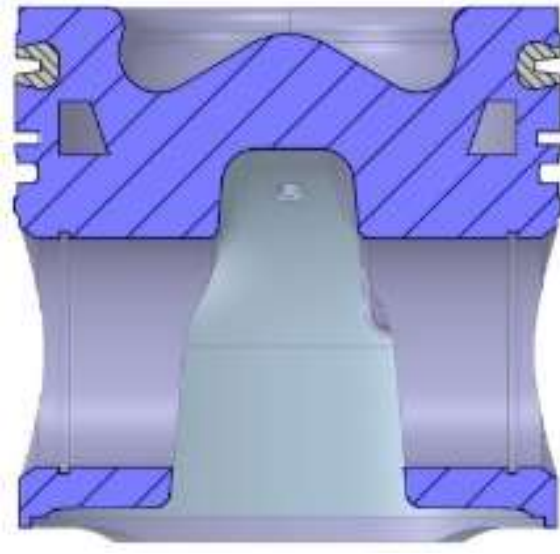

(b)

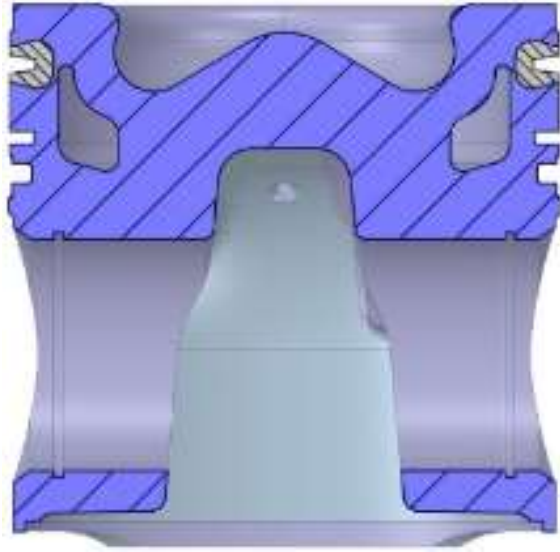

(c)

Figure2: a) First Design b) Second Design c) Third Design

\subsection{Realization of the Analyzes}

Steady-state thermal analysis is based on the Fourier Law equation. This means that the thermal analysis solved by the simulation is a transmission-based equation. The heat flow within a solid form the basis of Fourier's Law. In this type of analysis, temperature-dependent heat transfer coefficients can be entered for convective boundary conditions. For this reason, this type of analysis is considered suitable for this study. The designed pistons are loaded on steady-state thermal analysis in the ANSYS software.

Steady-state thermal analysis consists of six parts. First, the desired materials are selected from the engineering data section, where determines which the model materials to be formed. After the geometry section where the geometries are formed, the materials are applied to the model in the model section, coordinate system and connections are adjusted, and the piston regions can be meshed according to the regions. In the setup section, a number of data such as heat flow, temperature, heat transfer coefficient and combustion data are defined on a certain surface according to the piston regions.

In this study, it is not interested in combustion analysis, it is aimed to examine the change of heat flows in piston areas for three designs by using combustion data in idle operating conditions of $1000 \mathrm{rpm}$.

The piston material was selected from the aluminum alloy and the alfin was selected from gray cast iron. The regions of the piston were then named in detail. The terms of the piston regions were used when naming. The top surface of the piston was as "top", the bending region in top surface was as "bowl rim", from the piston top surface to alfin area was as "top land", upper part of alfin was as "alfin top" bottom part of alfin was as "alfin bottom", the area between alfintop and alfinbottom was as "top groove", the area between top groove and mid groove was as "midland", mid groove was as "mid groove", the area between mid-groove and oil groove was as "oil land", oil groove was as "oil groove", pin boss was as "pin boss", the areas upper the pin boss were as 
"pinface1", "pinface2" and "pin face top", skirt area was as "skirt", the inner part of the skirt area was as "undercut", the inner part of the piston head was as "inner shape" and cooling gallery was as "cooling gallery" named.

After this nomenclature, suitable mesh structures are assigned to the regions named. Regional heat transfer coefficients values obtained from the literature have been defined in the named areas. In the solution section, the analyzes were performed by demanding the temperature of the entire piston structure, the cooling gallery, and the heat flows of all named piston regions.

\section{RESULTS AND DISCUSSION}

As a result of the analyzes, the desired results were obtained from the analysis and it was observed that general piston structure, pin boss, top groove and piston top surface temperature profiles are similar in all three designs and there are minor changes in the maximum and minimum temperature values.

Regional heat data of the designs were obtained. While the cooling galleries temperature profiles differ in contrast to the other regions of the piston, differences have been observed between the maximum and minimum temperature values.

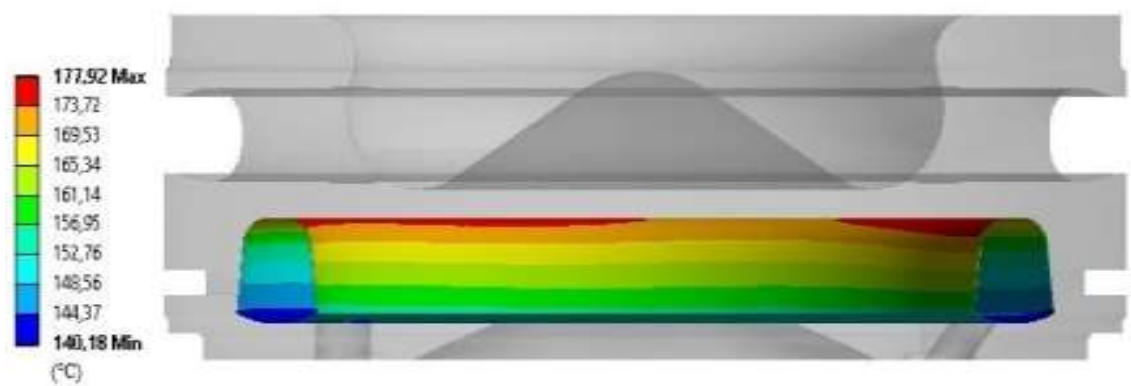

Figure3.a

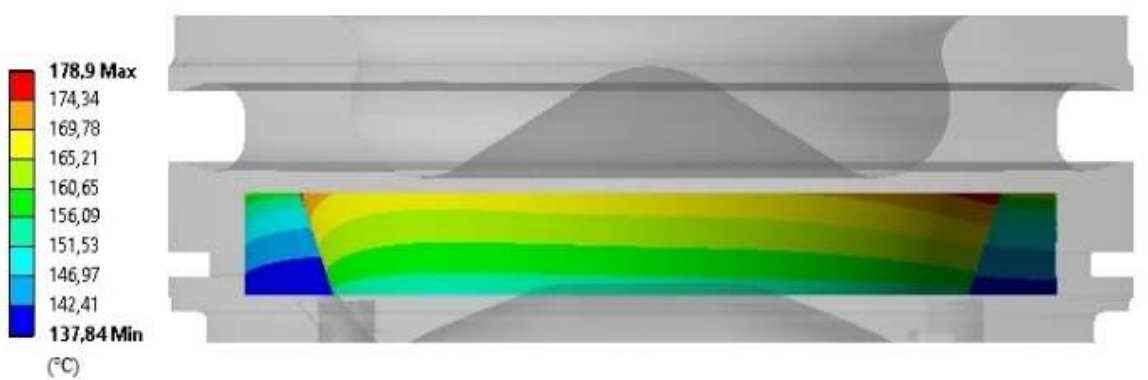

Figure3.b

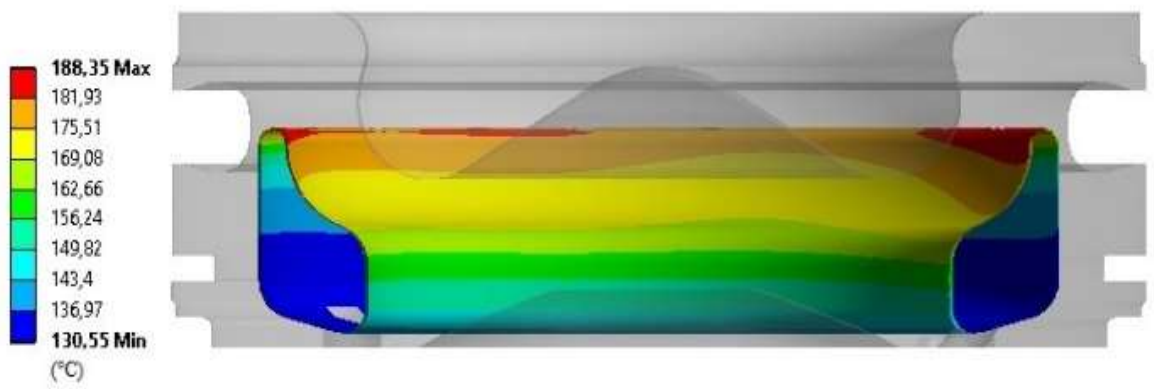

Figure3.c

Figure3: a) First Design Cooling Gallery Temperature Profile b) Second Design Cooling Gallery Temperature Profile c) Third Design Cooling Gallery Temperature Profile System

As a result of analysis, it was concluded that the ratio of heat discharged by the cooling gallery is equal to $38 \%$ in the first design, $42 \%$ in the second design and 55\% in the third design. In the literature, depending on the piston geometry and the types of cooling, the rate of heat discarded from the piston regions varies. Each piston and piston cooling geometry has separate reference 
values. In this study, the rate of heat rejected in all regions except for the heat rejection rate from the first design cooling gallery was observed conformity with the reference values in the literature.

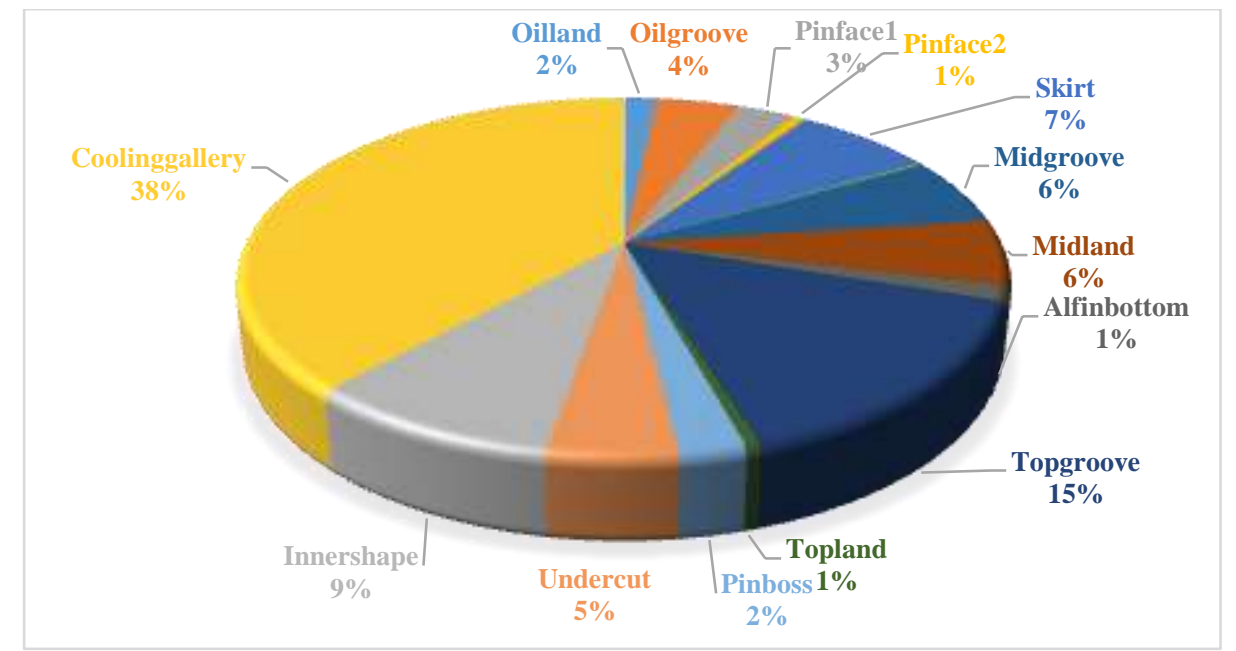

Figure 4.a

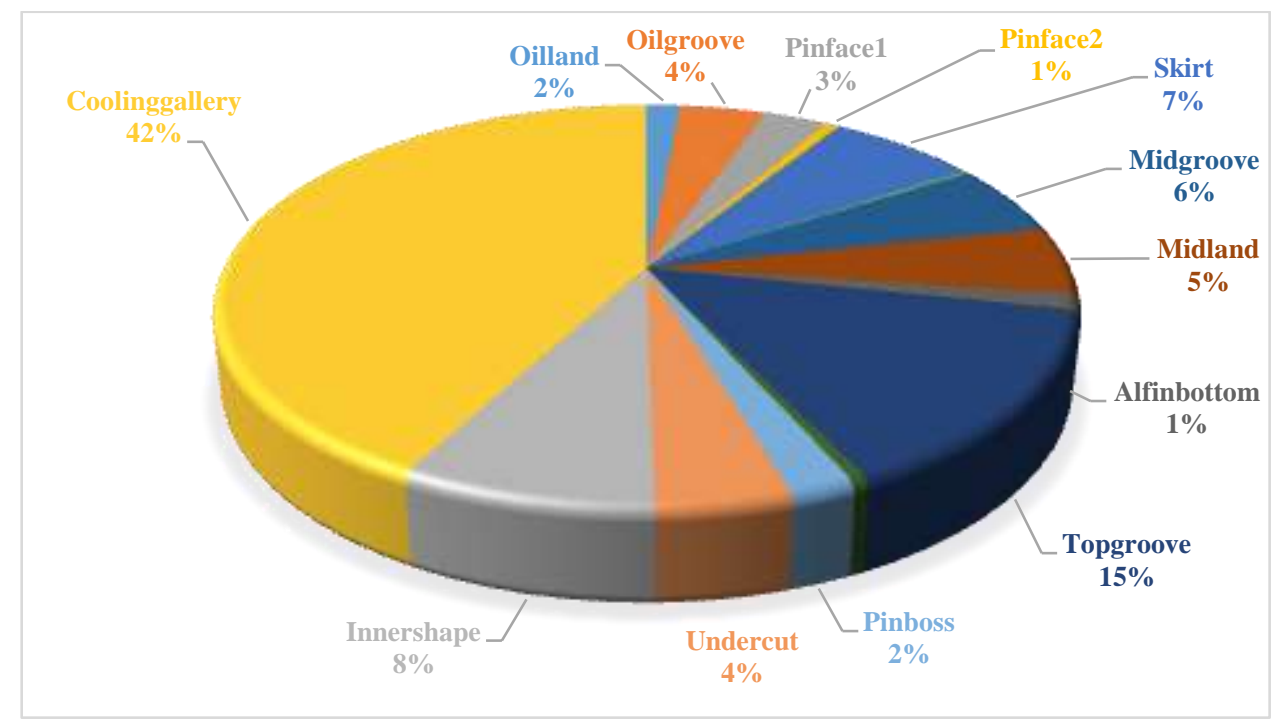

Figure 4.b

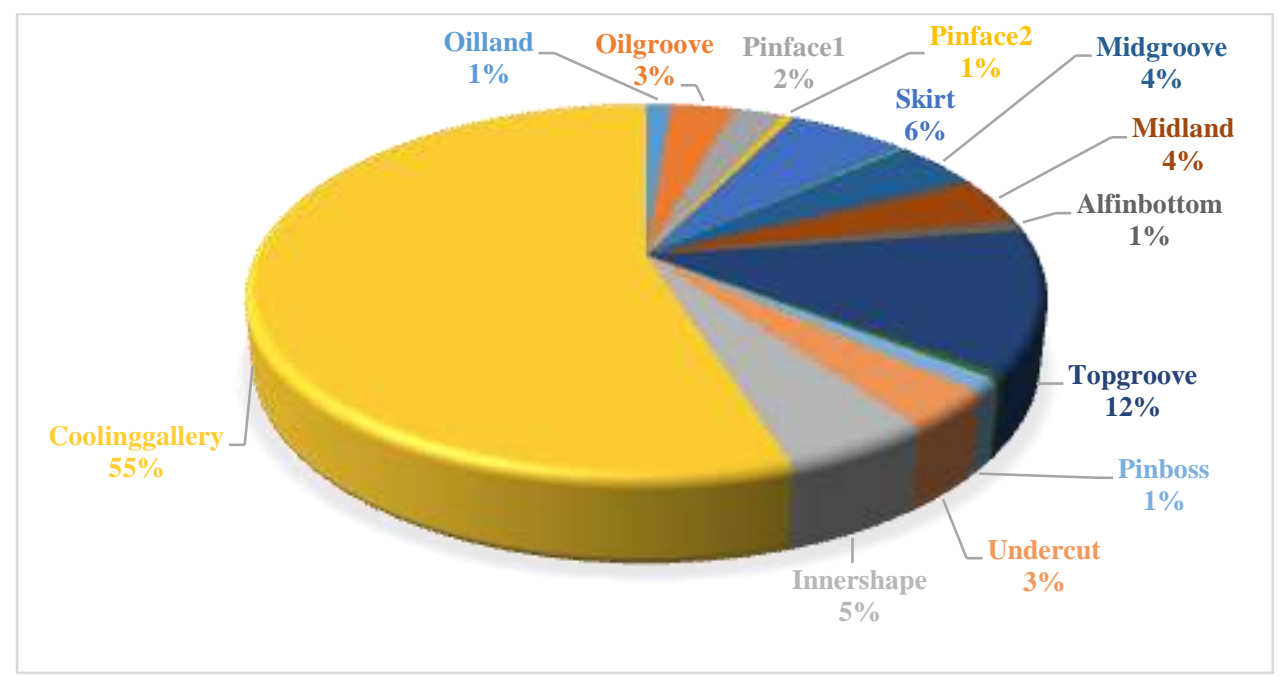

Figure 4.c

Figure4: a) Regional Distribution of Heat Flow in First Design b) Regional Distribution of Heat Flow in Second Design c) Regional Distribution of Heat Flow in Third Design 
In order to carry out the analysis, the piston was divided into several regions. As a result of the analysis, some of these regions were evaluated together and compared with the reference values. In the evaluation, the piston was examined six sections; the cooling gallery, ring zone which includes the areas of ring grooves and the areas between these grooves, the inner zone which includes regions of the undercut and inner shape, skirt zone, piston pin side surface and pin boss.

Table3. Heat Distribution Ratio Depend on Regions in First Design

\begin{tabular}{|c|c|c|}
\hline Piston Zones & $\begin{array}{c}\text { Heat Dissipation } \\
\text { Percentage }\end{array}$ & Reference Values \\
\hline Cooling Gallery & $38 \%$ & $40-60 \%$ \\
\hline Ring Zone & $35 \%$ & $25-45 \%$ \\
\hline Piston Inner Zone & $14 \%$ & $5-15 \%$ \\
\hline Piston Skirt & $7 \%$ & $5-10 \%$ \\
\hline Piston Pin Side Surface & $4 \%$ & $0-5 \%$ \\
\hline Pin Boss & $2 \%$ & $0-10 \%$ \\
\hline
\end{tabular}

Table4. Heat Distribution Ratio Depend on Regions in Second Design

\begin{tabular}{|c|c|c|}
\hline Piston Zones & $\begin{array}{c}\text { Heat Dissipation } \\
\text { Percentage }\end{array}$ & Reference Values \\
\hline Cooling Gallery & $42 \%$ & $40-60 \%$ \\
\hline Ring Zone & $33 \%$ & $25-45 \%$ \\
\hline Piston Inner Zone & $12 \%$ & $5-15 \%$ \\
\hline Piston Skirt & $7 \%$ & $5-10 \%$ \\
\hline Piston Pin Side Surface & $4 \%$ & $0-5 \%$ \\
\hline Pin Boss & $2 \%$ & $0-10 \%$ \\
\hline
\end{tabular}

Table5. Heat Distribution Ratio Depend on Regions in Third Design

\begin{tabular}{|c|c|c|}
\hline Piston Zones & $\begin{array}{c}\text { Heat Dissipation } \\
\text { Percentage }\end{array}$ & Reference Values \\
\hline Cooling Gallery & $55 \%$ & $40-60 \%$ \\
\hline Ring Zone & $26 \%$ & $25-45 \%$ \\
\hline Piston Inner Zone & $8 \%$ & $5-15 \%$ \\
\hline Piston Skirt & $6 \%$ & $5-10 \%$ \\
\hline Piston Pin Side Surface & $3 \%$ & $0-5 \%$ \\
\hline Pin Boss & $1 \%$ & $0-10 \%$ \\
\hline
\end{tabular}




\section{CONCLUSIONS AND DISCUSSIONS}

With this study, it has been concluded that the use of different types of cooling galleries in the same piston geometry may increase the rate of heat ejected from the cooling gallery and in other words may reduce the heat load discharged from the ring zone in particular.

By diversifying the cooling gallery design, it has been seen that the maximum temperatures in different parts of the piston can be reduced, thus allowing changes in the piston regions to be might according to the needs.

The design of the cooling gallery suitable for each piston, depending on the piston geometry and the expected performance of the engine, can positively affect the heat transfer.

\section{REFERENCES}

[1] H. K. Junker, Piston and Engine Testing, First Edition, Springer Wieveg Tubner, 2012, Berlin.

[2] M. B. Varghese, S. K. Goyal and A. K. Agarwal, "Numerical and Experimental Investigation of Oil Jet Cooled Piston", SAE Society of Automotive Engineers Technical Paper Series, 2005-01-1382, 2005.

[3] D. C. Luff, T. Law, P. J. Shayler and I. Pegg, "The Effect of Piston Cooling Jets on Diesel Engine Piston Temperatures, Emissions and Fuel Consumption”, SAE Society of Automotive Engineers Technical Paper Series, 2012-01-1212, 2012.

[4] N. Thiel, H. J. Weimar, H. Kamp and H. Windisch, "Advanced Piston Cooling Efficiency: A Comparison of Different New Gallery Cooling Concepts”, SAE Society of Automotive Engineers Technical Paper Series, 2007-01-1441, 2007.

[5] Y. Yi, M. Reddy, M. Jarret, P. S. C. Kinsey, T. Alcenius and K. Inal, "CFD Modeling of the Multiphase Flow and Heat Transfer for Piston Gallery Cooling System”, SAE Society of Automotive Engineers Technical Paper Series, 2007-01-4128, 2007.

[6] M. A. R. Belmonte, C. D. Copeland, D. Hislop, G. Hopkins, A. Schmieder, S. Bredda and A. Sam, "Improving Heat Transfer and Reducing Mass in a Gasoline Piston Using Additive Manufacturing", SAE Society of Automotive Engineers Technical Paper Series, 2015-01-0505, 2015.

[7] J. Kelleher and N. Ajotikar, "Piston Cooling Nozzle Oil Jet Evaluation Using CFD and a High Speed Camera", SAE Society of Automotive Engineers Technical Paper Series, 2016-01-8100, 2016.

[8] N. Zhu, F. Dong, M. Zong and J. Ni, "Simulation and Optimization on Oscillating Cooling Characteristics in High-Enhanced Piston Oil Cooling Gallery”, SAE Society of Automotive Engineers Technical Paper Series, 2017-01-1049, 2017.

[9] W. Peng, L. Jizu, B. Minli, W. Yugan, H. Chengzhi and Z. Liang, "Numerical Simulation on the Flow and Heat Transfer Process of Nanofluids Inside a Piston Cooling Gallery, An International Journal of Computation and Methodology, 65:4, 378-400, 2014.

[10] U. Canvar, "Structural and Thermal Analysis of Diesel Engine Piston with Finite Element Method", Master's Thesis, İstanbul Technical University, Graduate School of Science and Engineering, İstanbul, 2011. 